\title{
Circulating cathepsin S improves glycaemic control in mice
}

\author{
Hamzeh Karimkhanloo',2, Stacey N Keenan'1, Emily W Sun³, David A Wattchow², Damien J Keating3, \\ Magdalene K Montgomery ${ }^{1}$ and Matthew J Watt ${ }^{1}$
}

1Department of Physiology, University of Melbourne, Melbourne, Australia

2Metabolism, Diabetes and Obesity Program, Monash Biomedicine Discovery Institute, and Department of Physiology, Monash University, Clayton, Victoria, Australia

${ }^{3}$ Flinders Health and Medical Research Institute, Flinders University, Adelaide, South Australia, Australia

4Departments of Surgery and Gastroenterology, Flinders Medical Centre, Bedford Park, SA, Australia

Correspondence should be addressed to M J Watt: matt.watt@unimelb.edu.au

*(MK Montgomery and MJ Watt contributed equally as senior authors)

\begin{abstract}
Cathepsin S (CTSS) is a cysteine protease that regulates many physiological processes and is increased in obesity and type 2 diabetes. While previous studies show that deletion of CTSS improves glycaemic control through suppression of hepatic glucose output, little is known about the role of circulating CTSS in regulating glucose and energy metabolism. We assessed the effects of recombinant CTSS on metabolism in cultured hepatocytes, myotubes and adipocytes, and in mice following acute CTSS administration. CTSS improved glucose tolerance in lean mice and this coincided with increased plasma insulin. CTSS reduced G6pc and Pck1 mRNA expression and glucose output from hepatocytes but did not affect glucose metabolism in myotubes or adipocytes. CTSS did not affect insulin secretion from pancreatic $\beta$-cells, rather CTSS stimulated glucagonlike peptide (GLP)-1 secretion from intestinal mucosal tissues. CTSS retained its positive effects on glycaemic control in mice injected with the GLP1 receptor antagonist Exendin (9-39) amide. The effects of CTSS on glycaemic control were not retained in high-fatfed mice or $\mathrm{db} / \mathrm{db}$ mice, despite the preservation of CTSS' inhibitory actions on hepatic glucose output in isolated primary hepatocytes. In conclusion, we unveil a role for CTSS in the regulation of glycaemic control via direct effects on hepatocytes, and that these effects on glycaemic control are abrogated in insulin resistant states.
\end{abstract}

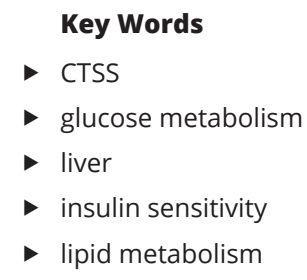

Journal of Endocrinology (2021) 248, 167-179

\section{Introduction}

Hepatokines are liver-secreted proteins that can signal to, and induce, metabolic effects in the liver and other peripheral tissues including adipose tissue, skeletal muscle and pancreas (Meex et al. 2015). Altered hepatokine secretion has been implicated in the development of the metabolic syndrome, non-alcoholic fatty liver disease (NAFLD), type 2 diabetes and cardiovascular disease by regulating a multitude of signalling cascades and inducing transcriptional changes in target tissues (Pal et al. 2012, Meex et al. 2015, Jung et al. 2016, Oh et al. 2016). Changes in hepatokine secretion in NAFLD can influence glycaemic control, insulin action, lipid metabolism and inflammation (Meex \& Watt 2017), and in this respect, several hepatokines including fetuin-A, fetuin-B, adropin, 
selenoprotein P and fibroblast growth factor 21 (FGF21) have been shown to directly impact these metabolic processes and contribute to associated pathologies (Meex \& Watt 2017, Watt et al. 2019).

Cathepsin family proteins are lysosomal peptidases categorised to the cysteine, serine and aspartic protease classes that have been shown to be secreted by some tissues, including the liver (Kuester et al. 2008). Within this family, cathepsin S (CTSS) is a potent cysteine protease that has been associated with several pathological states including arthritis, cancer, and cardiovascular disease (Wilkinson et al. 2015). A pathological feature of these disease states is increased CTSS secretion and enhanced enzymatic activity towards extracellular substrates (Wilkinson et al. 2015). In contrast to the other cathepsins, CTSS remains active and stable at neutral $\mathrm{pH}$, allowing for its activity to be conserved when secreted and thereby suggesting potential endocrine functions (Jordans et al. 2009). Circulating CTSS levels have been shown to be increased in individuals with type 2 diabetes (T2D), obesity and dyslipidemia (Liu et al. 2006, Taleb et al. 2006, Verrijn Stuart et al. 2012, Chen et al. 2013), and are reduced following weight loss (Taleb et al. 2006). In this respect, increased circulating CTSS levels may contribute to defects in glycaemic control, as deletion of Ctss or administration of orally active small-molecule CTSS inhibitors in mice improved glucose tolerance by reducing hepatic glucose production (HGP) (Lafarge et al. 2014) and attenuated the onset of type 1 diabetes (Hsing et al. 2010). While these studies are informative, the direct impact of circulating CTSS on glycaemic control and systemic metabolism is currently unknown. Accordingly, this study focused on understanding the endocrine role of CTSS and examined the effects of recombinant (circulating) CTSS in regulating glucose metabolism in cultured cells, tissues and mice.

\section{Materials and methods}

\section{Recombinant CTSS protein production and validation}

Murine CTSS recombinant protein was generated at Monash University Protein Production Unit (Melbourne, Australia) using a mammalian expression system (Expi293 cells) and purified under native conditions in $100 \mathrm{mM}$ $\mathrm{NaPO}_{4}$ and $150 \mathrm{mM} \mathrm{NaCl}$. Recombinant protein was freeze dried, resuspended at $0.5 \mathrm{mg} / \mathrm{mL}$, and stored at $-80^{\circ} \mathrm{C}$, avoiding repeated freeze-thawing. The presence of glycosylation was tested by immunoblotting of recombinant protein following PNGase $\mathrm{F}$ treatment (P7367, Sigma). Circular dichroism measurements were performed on an Applied Photophysics Chirascan spectrometer (Surrey, UK), using a $0.1 \mathrm{~cm}$ pathlength quartz cuvette. Measurements were performed at $20^{\circ} \mathrm{C}$, and samples were scanned from $190 \mathrm{~nm}$ to $260 \mathrm{~nm}$ in 1 $\mathrm{nm}$ step intervals and with $2 \mathrm{~s}$ averaging time. The data was analysed using DICHROWEB (Whitmore \& Wallace 2004), using the K2D algorithm (Andrade et al. 1993). CTSS protein activity was assessed using a fluorescencebased assay with the synthetic CTSS substrate VVR-AFC (Abcam, ab65307).

\section{Animal studies}

C57BL/6 male mice were housed at $22^{\circ} \mathrm{C}$ on a $12 \mathrm{~h}$ light:12 $\mathrm{h}$ darkness cycle and were fed either a rodent chow (5\% energy from fat) or a high-fat diet (HFD; 43\% energy from fat) (High Fat Rodent Diet SF04-001; Specialty Feeds) starting at 8-9 weeks of age for a total of 8 weeks. Diabetic $\mathrm{db} / \mathrm{db}$ mice (Jackson Laboratory strain: BKS.Cg-Dock7m +/+ Leprdb/J) were used at 8 weeks of age. Mice were fasted from 07:00 to 11:00 h before all experiments. Experimental procedures were approved by the University of Melbourne Anatomy \& Neuroscience, Pathology, Pharmacology, and Physiology Animal Ethics Committee (ethics no. 1814403) and conformed to the National Health and Medical Research Council of Australia guidelines regarding the care and use of experimental animals.

\section{Energy expenditure}

Whole-body energy expenditure, the respiratory exchange ratio, food intake and physical activity were assessed using a 16-chamber metabolic system (Promethion Metabolic System, Sable, Nevada, USA). Studies were commenced after $8 \mathrm{~h}$ of acclimation to the metabolic chamber. Expired gases were assessed at 30 min intervals for $48 \mathrm{~h}$. Mice received CTSS ( $1 \mathrm{mg} / \mathrm{kg}$ body weight) or saline injection i.p. $24 \mathrm{~h}$ following acclimatisation and were monitored for $24 \mathrm{~h}$ thereafter.

\section{Glucose and insulin tolerance tests}

Mice were fasted for $4 \mathrm{~h}$ prior to experiments. Recombinant CTSS (or saline control) was injected i.p. at $1.0 \mathrm{mg} / \mathrm{kg}$ body weight after $3 \mathrm{~h}$ fasting (i.e. $60 \mathrm{~min}$ before the oral glucose or i.p. insulin challenge). Mice were either gavaged orally with glucose $(2 \mathrm{~g} / \mathrm{kg}$ body weight) or injected i.p with insulin $(0.75 \mathrm{U} / \mathrm{kg}$ body weight, Actrapid). During the oral glucose tolerance test (OGTT), blood glucose levels 
were assessed at 0, 15, 30, 45, 60 and 90 min (Accu-Chek II glucometer; Roche Diagnostics), and additional blood was collected at 0, 15 and $30 \mathrm{~min}$ for later assessment of serum insulin and C-peptide levels (Ultra-Sensitive Mouse Insulin ELISA/Mouse C-peptide ELISA Kit; Crystal Chem, Elk Grove Village, IL, USA). During the insulin tolerance test (ITT), blood glucose levels were assessed at $-10,0$, 10, 20, 30 and $45 \mathrm{~min}$ after insulin injection. In separate experiments, the GLP1 receptor antagonist Exendin (9-39) amide (Abcam) was administered to mice (i.p. 4 $\mu \mathrm{g} / \mathrm{g}$ body weight) in the presence or absence of CTSS (i.p. $1.0 \mathrm{mg} / \mathrm{kg}$ body weight), and a GTT was performed as described previously.

\section{Assessment of CTSS and Cystatin C by ELISA}

CTSS secretion from murine liver slices, plasma CTSS and Cystatin C were assessed by ELISA (CTSS - Aviva System Biology, San Diego, USA; Cystatin C - Crystal Chem, Elk Grove Village, IL, USA). Plasma was obtained from mice following a $4 \mathrm{~h}$ fast. For secretion experiments, $300 \mu \mathrm{m}$ thick precision-cut liver slices were obtained from $4 \mathrm{~h}$ fasted $\mathrm{db}+$ and $\mathrm{db} / \mathrm{db}$ mice using a Krumdieck tissue slicer (TSE Systems GmbH, Germany) and secreted proteins were collected after $16 \mathrm{~h}$ incubation in EX-CELL® $325 \mathrm{PF}$ CHO Serum-Free Medium (Sigma Aldrich).

\section{Plasma CTSS levels in mice}

Mice were fasted for $4 \mathrm{~h}$, recombinant CTSS was injected (i.p.) at $1 \mathrm{mg} / \mathrm{kg}$ body weight, and blood samples were taken from a tail vein at $0,15,30,45,120,240$ and $480 \mathrm{~min}$. Plasma CTSS was assessed by immunoblotting (see below).

\section{Assessment of GLP1 in human intestinal samples}

\section{Ex vivo secretion assay procedures}

Surgical specimen collection Procedures were approved by the Southern Adelaide Clinical Human Research Ethics Committee. Tissue from the terminal ileum was collected from consented patients undergoing right hemicolectomy for colon cancer at Flinders Medical Centre and Flinders Private Hospital. Specimens from patients that were indicated for any form of inflammatory bowel disease were not collected for this study. Characteristics of the patients ( 4 men and 4 women) are: age $68 \pm 3.6$ years, BMI $29 \pm 2.1$ $\mathrm{kg} / \mathrm{m}^{2}$. Three patients had type 2 diabetes (one was dietcontrolled, two were metformin-treated). The specimens were immediately placed in oxygenated iced-cold Krebs buffer (in mM, $\mathrm{NaCl} 138, \mathrm{KCl} 4.5, \mathrm{CaCl}_{2} 2.6, \mathrm{NaHCO}_{3}$
4.2, $\mathrm{MgCl}_{2}$ 1.2, $\mathrm{NaH}_{2} \mathrm{PO}_{4}$ 1.2, HEPES 10, Glucose 5) and transported to the laboratory for dissection within 15 min with continuous carbogen bubbling. The specimens were rinsed with iced-cold Krebs buffer to remove any luminal content and dissected clear of adipose, muscular and connective tissue. The mucosae were gently separated from the submucosa using spring scissors, cut into pieces and weighed individually.

Ex vivo secretion assay Mucosal tissues were incubated with $100 \mu \mathrm{L}$ of assay buffer (modified Krebs buffer as above, supplemented with $1 \mu \mathrm{M}$ sitagliptin and $0.1 \%$ BSA) or assay buffer containing different stimulants in a 96-well plate for $15 \mathrm{~min}$ at $37^{\circ} \mathrm{C}$ in $95 \% \mathrm{O}_{2} / 5 \% \mathrm{CO}_{2}$. As such, secretion upon CTSS exposure was compared to that under control conditions (assay buffer only) in tissue from the same donor. Supernatants were collected and stored in aliquots at $-20^{\circ} \mathrm{C}$ until analysis. Active GLP1 levels were quantitated using a commercially available ELISA (EZGLPHS-35K, Merch Millipore, USA). 300 mM glucose was used as a positive control as we previously showed high extracellular glucose reliably stimulates GLP1 release from human small intestine (Kady et al. 2018).

\section{Cell culture}

C2C12 myoblasts were grown in DMEM (Gibco), containing $10 \%$ foetal bovine serum (Thermo Fisher Scientific) and antibiotics (100 units $/ \mathrm{mL}$ penicillin and $100 \mu \mathrm{g} / \mathrm{mL}$ streptomycin), as previously described (Montgomery et al. 2013). Differentiation was induced by serum starvation with $2 \%$ horse serum for 5-7 days.

3T3-L1 adipocytes were cultured in DMEM supplemented with $10 \%$ foetal bovine serum, $4 \mathrm{mM}$ L-glutamine and antibiotics (100 units $/ \mathrm{mL}$ penicillin and $100 \mu \mathrm{g} / \mathrm{mL}$ streptomycin), and once fully confluent, differentiation was induced with DMEM containing 10\% FBS, $0.4 \mu \mathrm{M}$ insulin, $0.25 \mu \mathrm{M}$ dexamethasone, and $0.5 \mathrm{mM}$ 3-isobutyl-1-methylxanthine (IBMX). After 3 days, the medium was replaced with DMEM containing $10 \%$ FBS and $0.4 \mu \mathrm{M}$ insulin for another 3 days, followed by overnight incubation in DMEM containing $0.5 \%$ FBS. Primary murine hepatocytes were isolated from 8-week-old chow mice and 12-week-old $\mathrm{db} / \mathrm{db}$ mice by collagenase digestion, as previously described (Montgomery et al. 2015).

\section{Assessment of substrate metabolism in vitro}

C2C12 myotubes, 3T3-L1 adipocytes cells and primary murine hepatocytes were incubated with CTSS $(100 \mathrm{pg} / \mathrm{mL}$, 
$10 \mathrm{ng} / \mathrm{mL}$ and $1 \mu \mathrm{g} / \mathrm{mL}$ ) for $2 \mathrm{~h}$ prior to the assessment of glucose metabolism and glucose uptake using radiolabelled substrates.

\section{Glucose oxidation and glycogen synthesis}

Cells were incubated in high-glucose DMEM containing $0.2 \%$ BSA and $1 \mu \mathrm{Ci} / \mathrm{mL} \mathrm{U-14} \mathrm{C}$-glucose (Perkin Elmer) for $2 \mathrm{~h}$. Thereafter, the media was acidified in $0.5 \mathrm{~mL}$ of $1 \mathrm{M}$ perchloric acid and the escaped $\mathrm{CO}_{2}$ captured in $200 \mu \mathrm{L} 1 \mathrm{M} \mathrm{NaOH}$. The radioactivity within the $\mathrm{NaOH}$ fraction (representing the rate of glucose oxidation) was counted on a scintillation counter (TRI-CARB 4910TR 110 $\mathrm{V}$ Liquid Scintillation Counter, Perkin Elmer). The tissue homogenate was incubated in $100 \mu \mathrm{L} 2 \mathrm{M} \mathrm{KOH}$ at $70^{\circ} \mathrm{C}$ for $20 \mathrm{~min}$. Following digestion, $75 \mu \mathrm{L}$ of saturated $\mathrm{Na}_{2} \mathrm{SO}_{4}$ and $1.3 \mathrm{~mL}$ of $98 \%$ ethanol was added on ice in order to precipitate glycogen. Samples were centrifuged at $16,000 \boldsymbol{g}$ for $10 \mathrm{~min}$ at $4^{\circ} \mathrm{C}$ to pellet glycogen. The pellet was dissolved in $200 \mu \mathrm{L}$ dd $_{2} \mathrm{O}$, glycogen precipitated again through the addition of $98 \%$ ethanol and centrifugation. The glycogen pellet was air-dried and resuspended in 200 $\mu \mathrm{L}$ of a solution containing $0.3 \mathrm{mg} / \mathrm{mL}$ amylo-glucosidase in $0.25 \mathrm{M}$ acetate buffer, $\mathrm{pH} 4.75$, and incubated overnight at $37^{\circ} \mathrm{C}$ to ensure full digestion of glycogen into glycosyl units. This digest was used for assessment of glycogen synthesis (i.e. presence of radioactivity) and for assessment of total glycogen (i.e. presence of glucosyl units) using a glucose oxidase kit (Infinity ${ }^{\mathrm{TM}}$ Glucose $(\mathrm{Ox})$, Fisher Scientific, USA).

\section{Glucose output}

Primary murine hepatocytes were incubated without or with CTSS $(10 \mathrm{ng} / \mathrm{mL})$ in glucose-free DMEM, supplemented with $10 \mathrm{mM}$ pyruvate for $24 \mathrm{~h}$, followed by the assessment of glucose in the media using a glucose oxidase assay kit (Infinity ${ }^{\mathrm{TM}}$ Glucose $(\mathrm{Ox})$, Fisher Scientific, USA). In separate experiments, hepatocytes were incubated for $8 \mathrm{~h}$ under the same conditions for the determination of $G 6 p c$ and $P c k 1$ expression by qRT-PCR.

\section{Glucose-stimulated insulin secretion (GSIS)}

MIN6 pancreatic $\beta$-cells were cultured in DMEM containing $10 \%$ FBS and antibiotics (100 units/mL penicillin and $100 \mu \mathrm{g} / \mathrm{mL}$ streptomycin). Prior to GSIS assessment, the cells were starved in Krebs Ringer Buffer (KRB) containing $0.25 \%$ BSA and $2.8 \mathrm{mM}$ glucose for 30 min, followed by incubation in KRB with $2.8 \mathrm{mM}$ (low) or $16.8 \mathrm{mM}$ (high) glucose for $1 \mathrm{~h}$. Insulin secreted into the media was measured by ELISA (Ultra-Sensitive Mouse
Insulin ELISA Crystal Chem, Elk Grove Village, IL, USA) and corrected for cell protein content.

\section{Immunoblot analysis}

Cell lysates and plasma were prepared in RIPA buffer, proteins were resolved by SDS-PAGE electrophoresis and conventional immunoblotting procedures were conducted as described previously (Mohktar et al. 2016). Proteins were visualised using Image Lab software version 6.0.1 (Bio-Rad Laboratories), and density was quantified by ImageJ software (version 1.52r). Antibodies used were Akt (Cell Signalling, 9272S), Akt Ser 473 (Cell Signalling, 4058S) and CTSS (Abcam, Ab232740). All antibodies were used as $1 / 1,000$ dilution (primary antibodies) or $1 / 10,000$ dilution (secondary antibodies).

\section{Gene expression analysis}

Total RNA was extracted from murine primary hepatocytes using TRI reagent (Sigma), treated with DNase (Ambion DNA free kit, Thermo Fisher) and reverse transcribed with iScript Reverse Transcriptase (Invitrogen). Gene expression was determined by CFX Connect $^{\text {TM }}$ Real-Time PCR Detection System (Bio-rad) using SYBR Green PCR Master Mix (Quantinova ${ }^{\circledR}$ SYBR Green PCR kit, Qiagen). Samples were normalised using Hprt as a housekeeping gene. Primer sequences were: Pck1 forward: 5'-AATATGACAACTGTTTGGCTG reverse: 5'-AATGCTTTCTCAAAGTCCTC; G6p forward: 5'-ACTGTGCATACATGTTCATC reverse: 5'-TGAATGTTT TGACCTAGTGC; Hprt forward: 5'-AGGGATTTGAA TCACGTTTG reverse: 5'-TTTACTGGCAACATCAAGAG.

\section{Statistical analysis}

Data are expressed as mean \pm s.e.M. Statistical analysis was performed by two-tailed unpaired t-test, one-way or two-way ANOVA followed by Bonferroni post hoc analysis (GraphPad Prism Version 7.04). The analysis used for specific experiments is outlined in the figure legends. Statistical significance was set $a$ priori at $P<0.05$.

\section{Results}

\section{Liver CTSS secretion and plasma CTSS levels in mice}

We first confirmed that CTSS is a bone fide hepatokine. CTSS was secreted from precision-cut liver slices of lean $\mathrm{db} /+$ mice and CTSS secretion was significantly increased in liver slices from $\mathrm{db} / \mathrm{db}$ mice with type 2 
diabetes (Fig. 1A). CTSS was readily detected in the plasma of mice using a commercial ELISA. Consistent with previous studies reporting increased CTSS in obesity and type 2 diabetes (Taleb et al. 2006, Chen et al. 2013), plasma CTSS tended to be increased in obese highfat-fed compared with chow-fed C57BL/6J mice (34\%, $P=0.06$; Fig. 1B), and in $\mathrm{db} / \mathrm{db}$ mice compared with lean normoglycaemic db/+ littermates (25\%, $P=0.06$; Fig. $1 \mathrm{C})$. We also assessed plasma levels of cystatin $C$, which is the most abundant and potent CTSS inhibitor (Wilkinson et al. 2015). Plasma cystatin C was unaltered in obese high-fat-fed mice compared with chow-fed C57BL/6J mice (Fig. 1D) and tended to be decreased in $\mathrm{db} / \mathrm{db}$ mice compared with db/+ littermates (19\%, $P=0.06$; Fig. 1E).

\section{CTSS improves glucose tolerance in lean mice}

To assess the effects of circulating CTSS on systemic metabolism, we generated recombinant murine CTSS protein. Protein structure assessment using circular dichroism spectrometry estimated CTSS to be $9 \% \alpha$-helix, $43 \% \beta$-sheet and $48 \%$ random coil, which is close to the predicted secondary structure elements and indicative of correct protein folding (Fig. 2A). In addition, we confirmed that recombinant CTSS was glycosylated (Fig. 2B) and, most importantly, enzymatically active (Fig. 2C). CTSS injected into lean C57BL/6 mice at $1 \mathrm{mg} / \mathrm{kg}$ body weight led to a two-fold increase in circulating CTSS 45 min after ip administration, which remained elevated for the $8 \mathrm{~h}$ duration of the experiment (Fig. 2D and E).

To assess the metabolic impact of circulating CTSS, we injected lean C57BL/6 mice with recombinant CTSS $1 \mathrm{~h}$ prior to metabolic assessments. Administration of CTSS did not affect fasting blood glucose levels but significantly improved glucose tolerance when compared to control mice (Fig. 3A). This improvement was accompanied by a transient increase in glucose-stimulated insulin secretion (Fig. 3B). CTSS administration did not affect insulin tolerance in lean mice (Fig. 3C).

To assess the effects of circulating CTSS on whole-body energy metabolism, mice were housed in Promethion metabolic cages for $48 \mathrm{~h}$. Whole-body oxygen consumption was increased 20 min after CTSS administration (Fig. 3D) and this increase was maintained throughout the experiment (Fig. 3E). The respiratory exchange ratio (RER) was not affected by CTSS administration (Fig. 3F and G), indicating no change in the proportion of carbohydrate and fatty acids being oxidised. Food intake (Fig. 3H) and physical activity (Fig. 3I) were not affected by CTSS.

\section{CTSS does not affect glucose metabolism in myotubes or adipocytes}

We utilised cell models to determine how CTSS improves glucose metabolism. CTSS did not affect glucose oxidation (Fig. 4A) or glycogen synthesis under basal conditions or following insulin stimulation (Fig. 4B) in C2C12 myotubes. CTSS increased Akt Ser473 phosphorylation in the basal state, however, CTSS did not affect Akt Ser473 following insulin stimulation (Fig. 4C and D). Consistent with a lack of effect of CTSS on glucose metabolism in skeletal myotubes, CTSS did not affect basal or insulinstimulated glucose uptake in 3T3-L1 adipocytes (Fig. 4E).

\section{CTSS reduces hepatic glucose production}

Studies in primary murine hepatocytes showed that CTSS significantly reduced hepatic glucose output when compared to control under basal conditions. There were

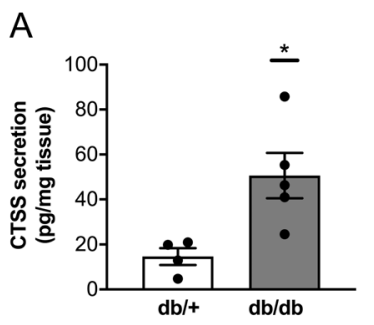

$\mathrm{B}$

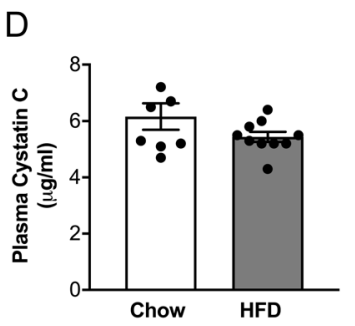

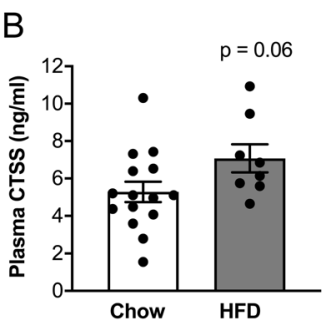

E
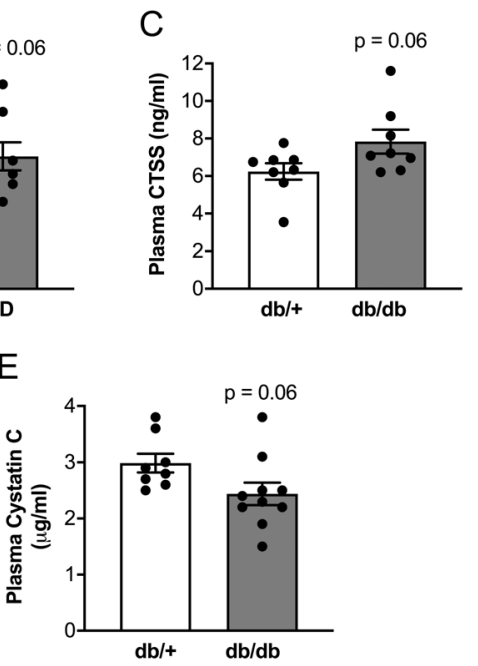

Figure 1

Liver CTSS secretion and plasma CTSS and Cystatin C levels in mice. (A) CTSS secretion from liver slices collected from lean $\mathrm{db}+(n=5)$ and $\mathrm{db} / \mathrm{db}$ mice with T2D $(n=5)$. (B) Plasma CTSS in $4 \mathrm{~h}$ fasted chow-fed $(n=15)$ and HFD-fed mice $(n=8)$. (C) Plasma CTSS in $4 \mathrm{~h}$ fasted lean $\mathrm{db}+$ mice $(n=8)$ and $\mathrm{db} / \mathrm{db}$ mice with T2D $(n=8)$. (D) Plasma Cystatin C in $4 \mathrm{~h}$ fasted chow-fed $(n=7)$ and HFD-fed mice $(n=10)$. (E) Plasma Cystatin C in $4 \mathrm{~h}$ fasted lean $\mathrm{db}+$ mice $(n=8)$ and $\mathrm{db} / \mathrm{db}$ mice with T2D $(n=10)$. Statistical analysis was performed by two-tailed unpaired Student's $t$ test. Values are means \pm S.E.M. ${ }^{\star} P<0.05$. 
A

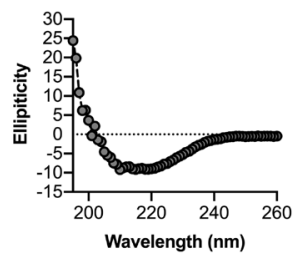

D

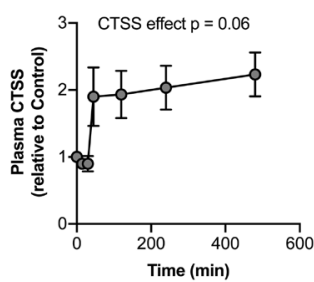

A

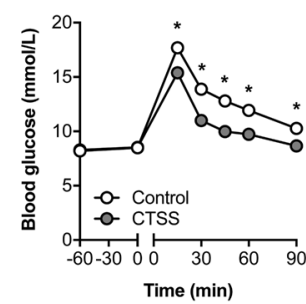

$\mathrm{D}$
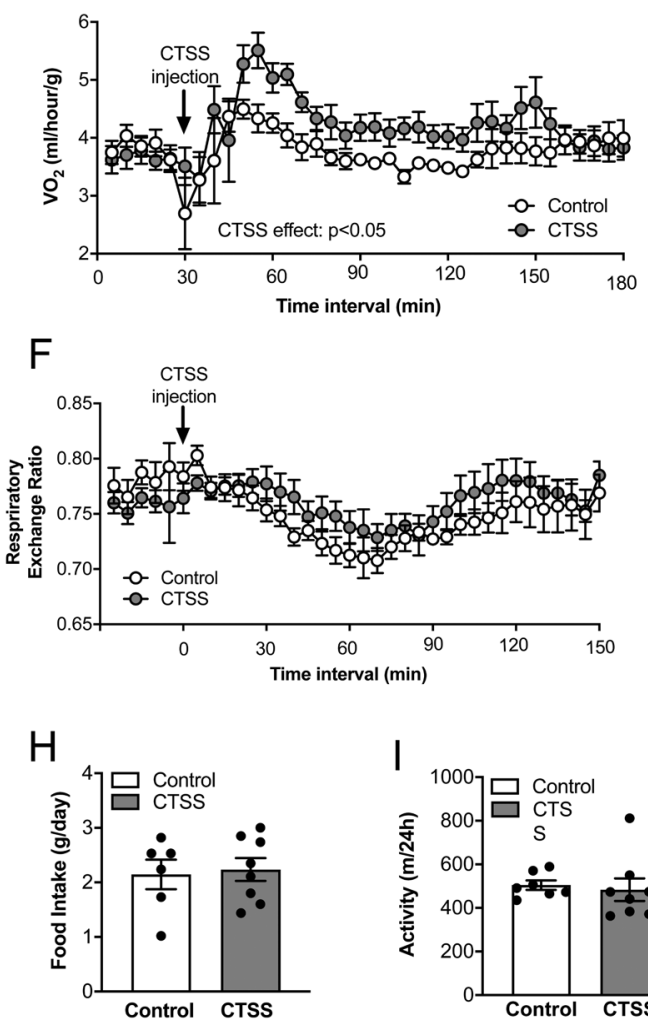

B

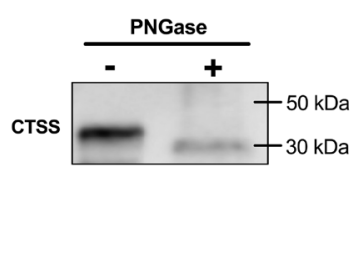

E

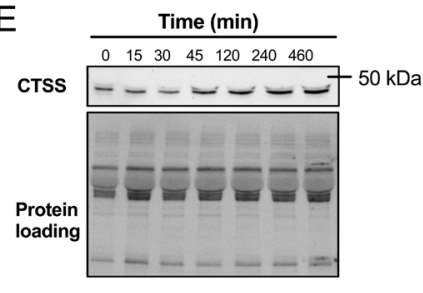

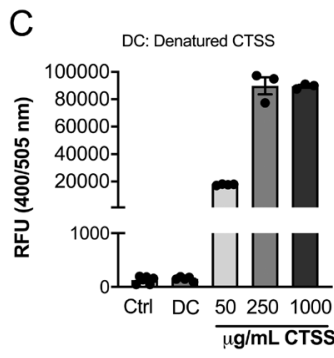

B

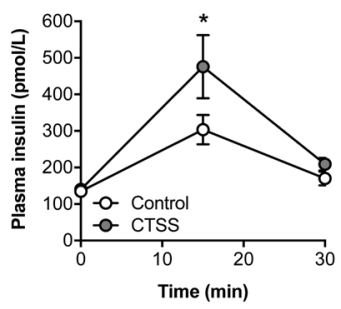

C

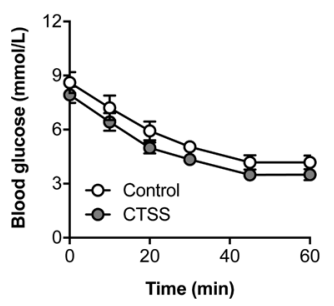

$E$

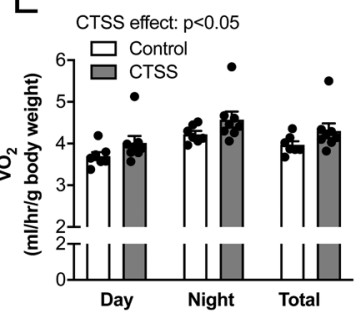

G

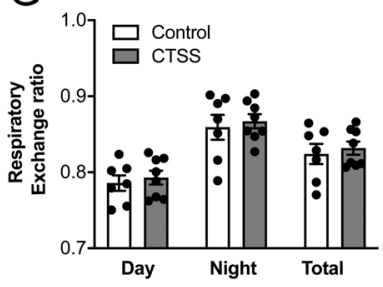

Figure 2

Validation of recombinant CTSS protein. (A) Circular dichroism spectrometry analysis of purified recombinant CTSS. (B) Immunoblot showing bandshift of CTSS after removal of glycosylation with PNGase F. Representative of three independent experiments. (C) Enzyme activity of recombinant CTSS; Ctrl is water and DC is denatured protein $(n=3-5$ per condition from duplicate experiments). (D and E) Plasma CTSS levels in mice before and after intraperitoneal CTSS injection (1 mg/kg body weight) in C57BL/6 mice ( $n=4$ mice). Statistical analysis was performed by one-way repeated measures ANOVA. Values are means \pm S.E.M.

\section{Figure 3}

CTSS effects on glucose metabolism and energy homeostasis in mice. (A, B and C) Lean mice were injected with recombinant CTSS protein $(1 \mathrm{mg} / \mathrm{kg}$ body weight) or saline control $60 \mathrm{~min}$ before metabolic assessment. (A) Oral glucose tolerance test (OGTT) (CTSS $n=42$, saline $n=42$ ), (B) plasma insulin during the OGTT (CTSS $n=29$, Saline $n=$ 30) and (C) insulin tolerance test (ITT) (CTSS $n=9$, Saline =9). (D, E, F, G, H and I) Mice were placed in Promethion metabolic cages and after an $8 \mathrm{~h}$ acclimatisation period were injected with CTSS ( $1 \mathrm{mg} / \mathrm{kg}$ body weight) or saline control. Mice were assessed for $48 \mathrm{~h}$ following injection. (D) Whole-body oxygen consumption $\left(\mathrm{VO}_{2}\right)$ highlighting the $2.5 \mathrm{~h}$ period after CTSS injection and $(\mathrm{E})$ average $\mathrm{VO}_{2}$. (F) Respiratory exchange ratio before and $2.5 \mathrm{~h}$ after CTSS injection (time of injection indicated with arrow) and (G) average RER. (H) Food intake and (I) physical activity (CTSS $n=8$, Saline $n=6$ ). Statistical analysis was performed by two-way ANOVA (A, B, C, D, E, F and $\mathrm{G})$, or unpaired two-tailed t-tests ( $\mathrm{H}$ and $\mathrm{I})$. Values are means \pm S.E.M. $* P<0.05$. 
A

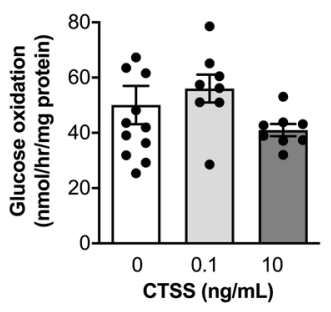

D

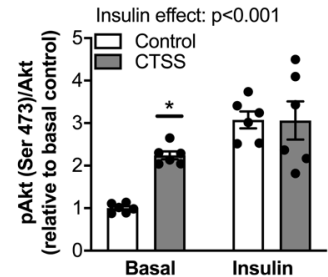

B

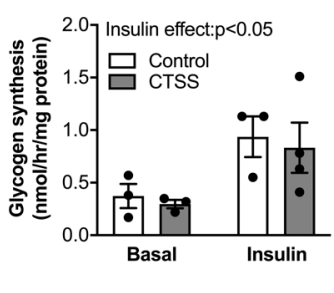

C

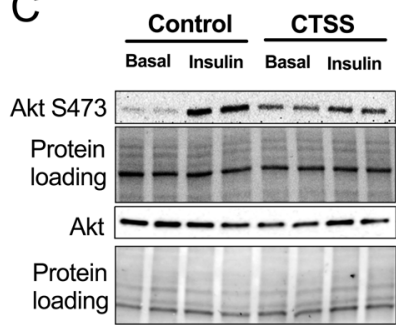

E

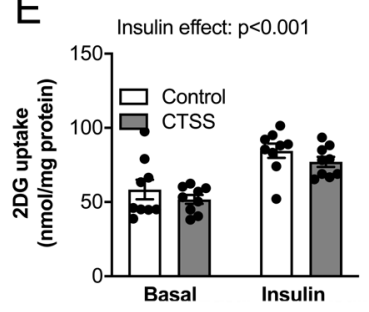

no significant differences between CTSS and control with insulin stimulation (Fig. 5A). Consistent with these findings, the expression of the gluconeogenic gene G6pc (Fig. 5B) was significantly reduced by $50 \%$ with CTSS compared with control under basal conditions. Pck1 tended to be reduced by CTSS under basal conditions $(P=0.052)$ (Fig. 5C). Insulin reduced G6pc and Pck1 expression to similar levels in control and CTSS treated hepatocytes (Fig. 5B and C). CTSS did not affect the rate of glycogen synthesis under basal or insulin-stimulated conditions (Fig. 5D) or glucose oxidation (Fig. 5E). Together, these data indicate that CTSS suppresses glucose
A

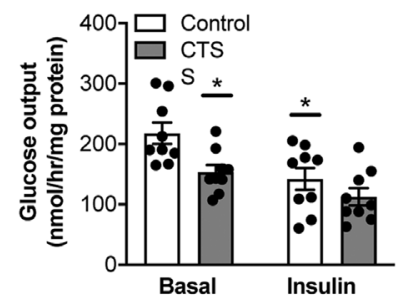

D

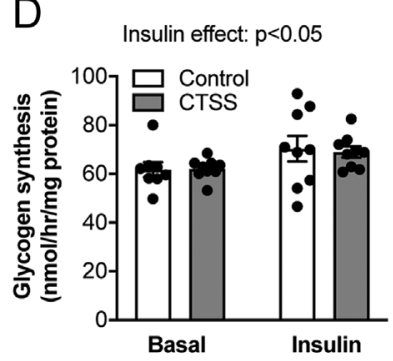

B

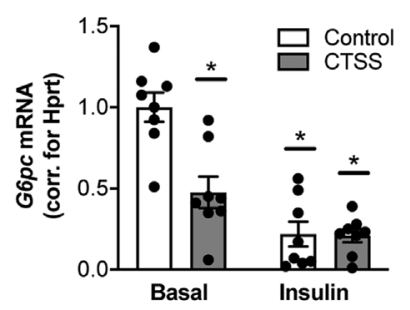

$E$

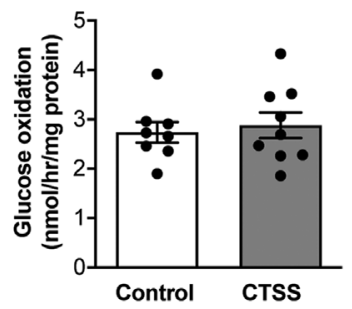

$(2 \cdot 2$

\section{Figure 4}

CTSS does not affect glucose metabolism in myotubes or adipocytes. CTSS was applied to C2C12 myotubes and 3T3-L1 adipocytes at $10 \mathrm{ng} / \mathrm{mL}$, unless otherwise stated, for $2 \mathrm{~h}$ prior to metabolic assessment. (A) Glucose oxidation $(n=8)$, (B) basal and insulin-stimulated glycogen synthesis ( $n=3)$, and (C and D) Akt (Ser 473) signalling $(n=6)$ in C2C12 myotubes. (E) Basal and insulin-stimulated glucose uptake in 3T3-L1 adipocytes $(n=9)$. Statistical analysis was performed by one-way (A) and two-way ANOVA (B, C, D and E) with Bonferroni post hoc tests. Values are means \pm S.E.M. $* P<0.05$.

output by reducing hepatic gluconeogenesis under noninsulin stimulated conditions. Consistent with this finding CTSS significantly increased Akt S473 phosphorylation in primary murine hepatocytes under basal conditions (i.e. not insulin stimulated) (Fig. 5F and G).

\section{CTSS does not affect insulin secretion in murine pancreatic $\beta$-cells}

Acute CTSS administration increased circulating insulin levels in lean mice (Fig. 3B). To determine whether CTSS directly affects pancreatic insulin secretion, we administered

C
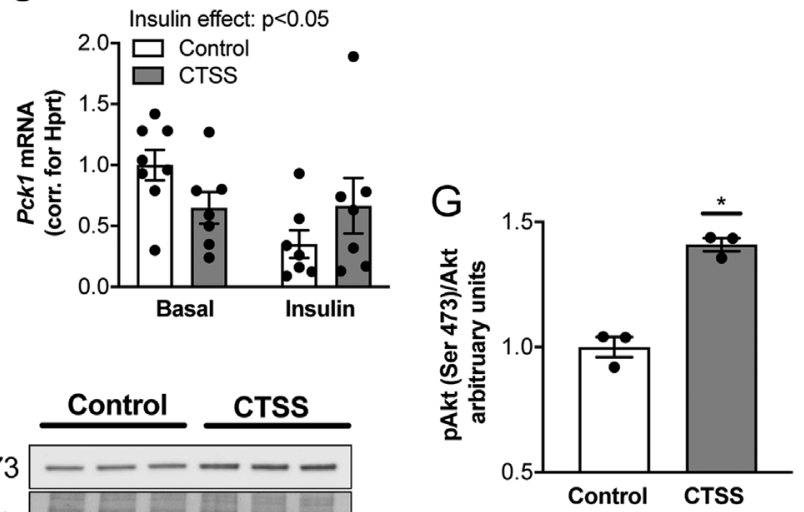

Figure 5

CTSS reduces hepatic glucose production in primary murine hepatocytes. Basal and insulin-stimulated (A) glucose output, mRNA expression of (B) G6pc and (C) Pck1 ( $n=9)$; (D) glycogen synthesis $(n=9)$ and (E) glucose oxidation $(n=9)$. (F and G) Akt (Ser 473) phosphorylation/total Akt protein content $(n=3)$. Statistical analysis was performed by two-way ANOVA (A, B, C and D) or unpaired two-tailed t-test $(E$ and F). Values are mean \pm S.E.M. * $P<0.05$. 
CTSS to murine MIN6 pancreatic $\beta$-cells and assessed basal and glucose-stimulated insulin secretion. While glucose significantly increased insulin secretion, CTSS did not have any effect on basal or glucose-stimulated insulin secretion, at any dose examined (Fig. 6A).

\section{CTSS increases GLP1 secretion, but this effect is dispensable for glycaemic control}

Based on the apparent contrasting results in cultured $\beta$-cells and mice, we next asked whether CTSS could be driving insulin secretion by regulating incretin hormone secretion, which enhances insulin secretion following carbohydrate ingestion (Nauck \& Meier 2018). To test this, we incubated human intestinal samples with CTSS or glucose. GLP1 was reliably detected in all secretion supernatants and 300 $\mathrm{mM}$ glucose significantly increased GLP1 secretion (Fig. 6B). CTSS administration increased GLP1 secretion to a greater extent than glucose, with effects seen at $10 \mathrm{ng} / \mathrm{mL}$ CTSS (Fig. 6B), a concentration that approximates plasma values in mice (Fig. 1B and C). Of note, we were not able to detect gastric inhibitory polypeptide (GIP) in the human
A
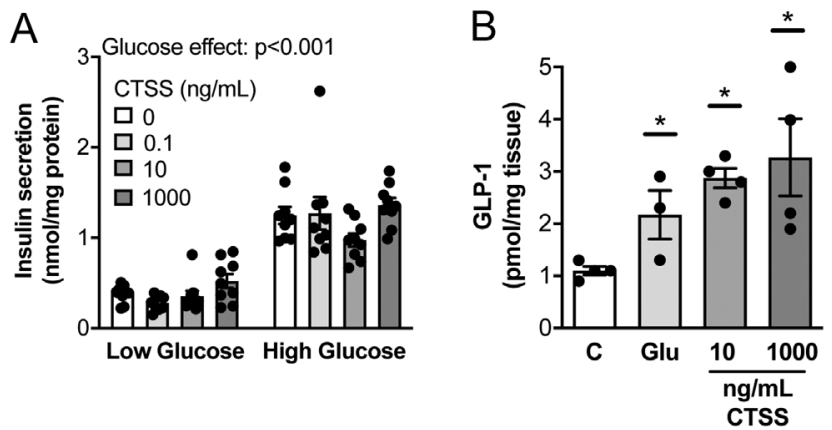

C $\circ$ control

- Exendin(9-39)

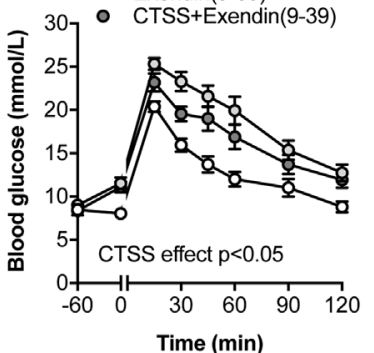

D

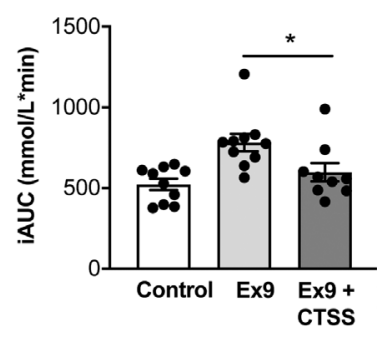

Figure 6

CTSS has GLP1- dependent and -independent effects on glycaemic control. (A) Insulin secretion in murine MIN6 pancreatic beta cells with low (2.8 $\mathrm{mM})$ and high-glucose (16.8 mM) $(n=9)$. (B) Basal and glucose-stimulated (300 mM glucose) GLP1 secretion in human intestinal explants $(n=8)$. (C and D) Exendin (9-39) and/or CTSS were injected 60 min before an oral glucose tolerance test in lean chow-fed C57BL/6 mice ( $n=10$ per group). Statistical analysis was performed by two-way ANOVA (A and C), a paired one-way ANOVA with Fishers Least Significant Difference post hoc test (B), or an unpaired two-tailed t-test (D). Values are mean \pm S.E.M. ${ }^{\star} P<0.05$. intestine secretion supernatants, which was expected as human tissues were obtained from the terminal ileum where enteroendocrine GIP-releasing K-cells have low abundance (Latorre et al. 2016).

CTSS improves oral glucose tolerance concomitant with increased insulin secretion, and the ex vivo experiments in intestinal samples indicate that this may be mediated through CTSS-regulation of GLP1. To test this possibility in vivo, we injected lean mice with the GLP1 receptor antagonist Exendin (9-39) amide (Schirra et al. 1998), in the absence or presence of CTSS prior to an oral glucose challenge. Consistent with previous studies (Chambers et al. 2017), Exendin (9-39) caused marked glucose intolerance in mice whereas co-administration of CTSS significantly improved glucose tolerance in Exendin (9-39) treated mice (Fig. 6C and D). These results suggest that, while CTSS has the capacity to induce GLP1 secretion in an ex vivo system, the CTSS-GLP1 axis does not appear to be the primary mechanism mediating CTSS' positive effects on glycaemic control in mice.

\section{CTSS does not improve glycaemic control in mice with T2D}

Based on the finding that CTSS improved glucose tolerance in lean mice, we next assessed the effects of acute CTSS administration on glucose metabolism and glycaemic control in obese $\mathrm{db} / \mathrm{db}$ mice with T2D. CTSS regulated glucose metabolism in cultured primary hepatocytes isolated from $\mathrm{db} / \mathrm{db}$ mice. Specifically, CTSS reduced basal HGP (Fig. 7A), increased glucose oxidation (Fig. 7B), and increased glycogen synthesis and glycogen content when compared to untreated hepatocytes (Fig. 7C and D). This demonstrates that CTSS effects on glucose metabolism are maintained in hepatocytes obtained from mice with type 2 diabetes. Insulin did not impact any of these measures which is indicative of the pronounced insulin resistance in $\mathrm{db} / \mathrm{db}$ hepatocytes (Fig. 7A, B, C and D). In contrast to these pronounced effects in vitro, acute CTSS administration did not affect glucose tolerance or plasma insulin levels in $\mathrm{db} / \mathrm{db}$ mice (Fig. 7E and F). This response was conserved in a second model of insulin resistance, where CTSS administration had no effect on glycaemic control in high-fat-fed mice that were obese and insulin resistant (Fig. 7G and $\mathrm{H}$ ).

\section{Discussion}

Cathepsin S plays an important role in the degradation of damaged proteins within the endo-lysosomal pathway. 
A

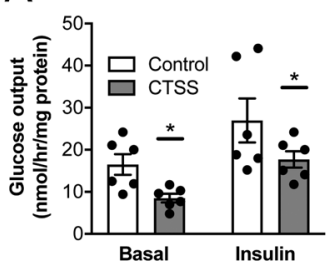

D

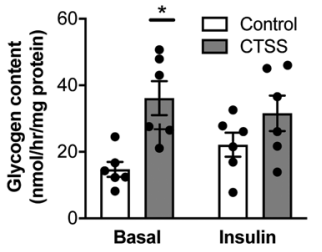

B

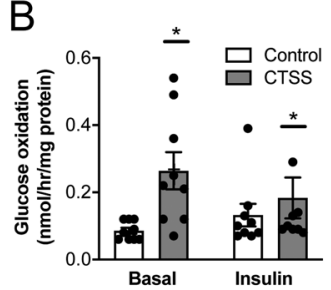

$E$

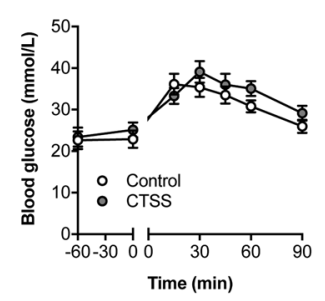

C CTSS effect $p<0.05$

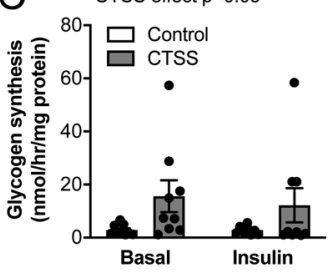

$\mathrm{F}$

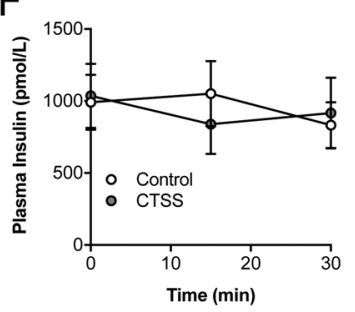

Figure 7

CTSS does not improve glycaemic control in mice with type 2 diabetes. (A, B, C and D) Primary hepatocytes were isolated from $\mathrm{db} / \mathrm{db}$ mice, followed by assessment of CTSS effects on (A) glucose output $(n=6)$, (B) glucose oxidation $(n=9),(C)$ glycogen synthesis $(n=9)$ and (D) glycogen content $(n=6)$. ( $E$ and F) db/db mice were injected with CTSS ( $1 \mathrm{mg} / \mathrm{kg}$ body weight, i.p.) or saline control $60 \mathrm{~min}$ before (E) an oral glucose tolerance test (OGTT) ( $n=14$ per group). (F) Plasma insulin during OGTT ( $n=14$ per group). ( $G$ and H) C57BL/6 mice were fed a high-fat diet for 8 weeks followed by acute CTSS injection ( 1 $\mathrm{mg} / \mathrm{kg}$ body weight, i.p.) $60 \mathrm{~min}$ before (G) OGTT ( $n=8$ per group). (H) Plasma insulin during OGTT ( $n=8$ per group). Statistical analysis was performed by two-way ANOVA and Bonferroni post hoc analysis. Values are mean \pm S.E.M. $\star P<0.05$ vs control.
Extending beyond this critical function in protein turnover, recent evidence suggests that CTSS contributes to a wide range of physiological processes (Wilkinson et al. 2015). Here, we show that CTSS is a bona fide liversecreted protein that improves glycaemic control by reducing hepatocyte gluconeogenesis and glucose output. CTSS increased GLP1 secretion but this effect appears to be dispensable for CTSS effects on glycaemic control.

While CTSS is primarily localised to the lysosome, several lines of evidence support its role as an extracellular protein including the presence of a N-terminal signal peptide in its protein sequence, evidence that it is secreted from cells (Vidak et al. 2019), and stability at physiological $\mathrm{pH}$, which distinguishes CTSS from other cathepsins (Wilkinson et al. 2015). Consistent with this notion, we report secretion from murine liver, although our studies cannot distinguish between secretion from hepatocytes and non-parenchymal cells. With previous studies demonstrating no secretion of CTSS from isolated hepatocytes and limited expression in antigen-presenting cells (Rawlings \& Salvesen 2012), it is likely that CTSS is secreted from liver resident sinusoidal endothelial cells, stellate cells, various myeloid and lymphoid cell population, cholangiocytes, mast cells or neutrophils (Mehrfeld et al. 2018). We also show that CTSS secretion is increased by 2.5 -fold from livers of $\mathrm{db} / \mathrm{db}$ mice and that circulating CTSS levels are increased in obese insulin resistant $\mathrm{db} / \mathrm{db}$ and high-fat-fed mice, which agrees with previous reports in mice (Xu et al. 2013) and humans (Kuester et al. 2008, Hsing et al. 2010, Rogers et al. 2014, Maimaitiyiming et al. 2015). Together, this suggests that the liver may be a significant contributor to systemic CTSS levels, particularly in states of metabolic disease.

The magnitude of crosstalk between liver cells and other tissues in regulating hepatic and systemic metabolism is becoming better understood (Watt et al. 2019, Xiong et al. 2019). A notable finding from the present study is that CTSS improves glycaemic control in lean mice, which is associated with suppression of hepatic glucose output. The suppression of glucose output in isolated hepatocytes coincided with reduced expression of G6pc and Pck1, key regulators of gluconeogenesis, with no evidence that CTSS regulates other processes of hepatic or skeletal muscle carbohydrate metabolism including glycogen synthesis or glucose oxidation. It is presently unclear how CTSS suppresses hepatocyte glucose output, or whether CTSS suppresses hepatic glucose output in vivo, but this may be related to the known role of CTSS in proteolytic cleavage of various extracellular and cell surface proteins including CD47, E-cadherin, protease-activated receptor 2 (PAR-2), collagen, elastin or integrins (Wilkinson et al. 2015). PAR2 is abundantly expressed in hepatocytes and stellate cells of the liver (Shearer et al. 2016), and its deletion in mice leads to an increase in glycogen synthesis, a decrease in 
glycolysis and gluconeogenesis, and overall reduction in blood glucose levels (Wang et al. 2015, Rana et al. 2019). Similarly, CD47 knockout mice show improved glucose tolerance (Maimaitiyiming et al. 2015) and CD47 signalling was shown to inhibit VEGFR-mediated Akt phosphorylation (Rogers et al. 2014). While we did not assess CTSS effects on hepatic PAR2 or CD47 signalling, it is unlikely that CTSS improves glucose tolerance through these receptors as previous studies showed that CTSS activates PAR2 (Chung et al. 2019) and CD47-mediated (Lee et al. 2014) signalling pathways, with activation of such pathways being associated with impairments in glycaemic control.

A previous study showed that germline whole-body deletion of Ctss or chronic pharmacological inhibition of CTSS reduced fasting blood glucose and improved glucose tolerance in mice, which was associated with reduced expression of gluconeogenic genes and reduced hepatic glucose output, but no change in insulin sensitivity (Lafarge et al. 2014). Chronic Ctss deletion and pharmacological inhibition also increased insulin secretion, with the authors concluding that CTSS promotes 'pro-diabetic' alterations in the liver. It is perplexing that we have described a strikingly similar phenotype despite inducing the opposite effect; that is, acute upregulation of CTSS compared with long-term deletion/ inhibition. The discrepancies between these data sets are difficult to reconcile but may relate to transcriptome/ proteome adaptations with longer compared with acute interventions, as well as alterations induced by intracellular Ctss deletion compared with extracellular effects of the circulating protein. These data sets could therefore potentially distinguish the extracellular metabolic actions of CTSS and CTSS enzymatic activity within the lysosomal compartment.

GLP1 is produced and secreted by intestinal enteroendocrine L-cells and exerts powerful effects on insulin secretion, inhibits glucagon secretion at glucose concentrations above fasting levels and decelerates gastric emptying; factors that contribute to the blood glucoselowering effects of GLP1 (Drucker 2018). Our unexpected finding that GLP1 secretion was induced by CTSS is, to the best of our knowledge, the first evidence that a cathepsin family protein can regulate incretin hormone secretion. Indeed, our functional studies in human intestinal explants showed that CTSS potently induced GLP1 secretion to a similar magnitude as that induced by glucose administrated at concentrations usually seen by enteroendocrine L-cells after a meal (i.e. $50-500 \mathrm{mM}$ )
(Ferraris et al. 1990). While we speculate that CTSS most likely acts on enteroendocrine L-cells through cleavage and subsequent activation of CTSS substrates, such as PAR2, which is present in the intestinal epithelium and is highly expressed in the gastrointestinal tract (Sébert et al. 2019), the exact mode of action requires further, detailed mechanistic studies. Furthermore, while CTSS increased GLP1 secretion ex vivo, this mechanism appears to be dispensable for CTSS effects on glycaemic control in mice, as mice administered Exendin (9-39), a specific and competitive antagonist of GLP1, retained CTSSmediated improvements during an oral glucose tolerance test. The increase in GLP1 secretion with CTSS ex vivo was associated with CTSS-induced hyperinsulinemia during an oral glucose challenge in mice, supporting the notion that CTSS likely increases GLP1 secretion in vivo. However, as murine GLP1 is rapidly degraded following intestinal release as a result of endoproteolytic cleavage, with a peak at 1 min (Windeløv et al. 2017), we were not able to reliably assess GLP1 secretion in mice in vivo despite using two commercial ELISAs. The importance of GLP1 for glycaemic control is more broadly highlighted by our studies demonstrating marked impairments during an oral glucose tolerance test with administration of Exendin (9-39).

While this work identifies CTSS as a circulating protein that improves glycaemic control in lean mice, an unexpected finding was the complete ablation of these effects in obese, insulin resistant mice and $\mathrm{db} / \mathrm{db}$ mice with type 2 diabetes. This observation was intriguing in light of the established association between circulating CTTS levels and metabolic disease (Taleb et al. 2005, 2006, Liu et al. 2006, Naour et al. 2010), the reduction in CTSS following bariatric surgery and weight loss (Naour et al. 2010), and the improvement in glycaemic control in insulin resistant, high-fat-fed mice with Ctss deletion (Lafarge et al. 2014). It is unlikely that obese mice were refractory to CTSS effects due to 'CTSS resistance' in peripheral tissues, akin to insulin or leptin resistance in peripheral tissues (Steinberg \& Dyck 2000), because CTSS reduced glucose output and increased glucose oxidation and glycogen storage in hepatocytes isolated from $\mathrm{db} / \mathrm{db}$ mice. Interestingly, CTSS increased glycogen synthesis in hepatocytes isolated from $\mathrm{db} / \mathrm{db}$ mice but not lean mice. The lack of CTSS effects in hepatocytes from lean mice might be due to relatively high glycogen synthesis rates that are 10-15 times higher than hepatocytes from insulin-resistant $\mathrm{db} / \mathrm{db}$ mice. In this respect, previous studies have similarly reported reduced hepatic glycogen https://joe.bioscientifica.com

https://doi.org/10.1530/JOE-20-0408
(C) 2021 Society for Endocrinology Published by Bioscientifica Ltd.
Printed in Great Britain 
content in db/db mice (Gao et al. 2010, Yang et al. 2019). Finally, repeated administration of CTSS may be required to improve glycaemic control in diabetes and will be the focus of future investigation.

CTSS activity in the circulation is regulated by its inhibitor cystatin C (Wilkinson et al. 2015), but it is unlikely that increased CTSS degradation explains our in vivo observations, as plasma cystatin $\mathrm{C}$ was either unchanged or reduced in obese, insulin-resistant mice and $\mathrm{db} / \mathrm{db}$ mice, respectively. These findings align with previous studies suggesting either unchanged (Nørgaard et al. 2019) or decreased (Takiyama et al. 2018) plasma cystatin $\mathrm{C}$ levels in $\mathrm{db} / \mathrm{db}$ mice. It is possible that higher levels of circulating CTSS might be required to induce positive effects on glycaemic control in obese, insulinresistant mice or mice with T2D. However, it should be noted that the same relative amount of CTSS was injected into all mice ( $1 \mathrm{mg} / \mathrm{kg}$ mass), suggesting that circulating levels were likely to be higher in the heavier, obese mice whose excess weight is mostly adipose tissue.

In conclusion, we report an unexpected role for CTSS in the regulation of glycaemic control in mice, which appears to be mediated by direct suppression of glucose output from hepatocytes. We further show that CTSS induces GLP1 secretion, but this effect is dispensable for the beneficial effects of CTSS on glycaemic control. Future studies are warranted to assess CTSS substrates and mode of action within the intestine and liver.

\section{Declaration of interest}

The authors declare that there is no conflict of interest that could be perceived as prejudicing the impartiality of the research reported.

\section{Funding}

These studies were supported by funding from the National Health and Medical Research Foundation of Australia (NHMRC, APP1098972; APP1156508) and the Diabetes Australia Research Trust. M K M is supported by Research Fellowships from the NHMRC (APP1143224). H K is supported by Monash Graduate Scholarship (MGS) and Monash International Tuition Scholarship (MITS) (29302471).

\section{Author contribution statement}

$\mathrm{H} \mathrm{K}$ and $\mathrm{M} \mathrm{KM}$ designed research, performed research, analysed data and wrote the paper. S N K, E W S, D A W and D K performed research and analysed data. $\mathrm{M} J \mathrm{~W}$ designed research, analysed data and wrote the paper. M M and M W are co-last authors. All authors edited the manuscript and agreed to the final version of the manuscript.

\section{Acknowledgements}

This work was supported by infrastructure from the Melbourne Mouse Metabolic Phenotyping Platform (MMMPP) at the University of Melbourne and technical assistance from Vanessa Haynes.

\section{References}

Andrade MA, Chacon P, Merelo JJ \& Morán F 1993 Evaluation of secondary structure of proteins from UV circular dichroism spectra using an unsupervised learning neural network. Protein Engineering 6 383-390. (https://doi.org/10.1093/protein/6.4.383)

Chambers AP, Sorrell JE, Haller A, Roelofs K, Hutch CR, Kim KS, Gutierrez-Aguilar R, Li B, Drucker DJ, D'Alessio DA, et al. 2017 The role of pancreatic preproglucagon in glucose homeostasis in mice. Cell Metabolism 25 927.e3-934.e3. (https://doi.org/10.1016/j. cmet.2017.02.008)

Chen RP, Ren A \& Ye SD 2013 Correlation between serum cathepsin $\mathrm{S}$ and insulin resistance in type 2 diabetes. Experimental and Therapeutic Medicine 6 1237-1242. (https://doi.org/10.3892/ etm.2013.1290)

Chung K, Pitcher T, Grant AD, Hewitt E, Lindstrom E \& Malcangio M 2019 Cathepsin S acts via protease-activated receptor 2 to activate sensory neurons and induce itch-like behaviour. Neurobiology of Pain 6 100032. (https://doi.org/10.1016/j.ynpai.2019.100032)

Drucker DJ 2018 Mechanisms of action and therapeutic application of glucagon-like peptide-1. Cell Metabolism 27 740-756. (https://doi. org/10.1016/j.cmet.2018.03.001)

Ferraris RP, Yasharpour S, Lloyd KC, Mirzayan R \& Diamond JM 1990 Luminal glucose concentrations in the gut under normal conditions. American Journal of Physiology 259 G822-G837. (https://doi. org/10.1152/ajpgi.1990.259.5.G822)

Gao D, Nong S, Huang X, Lu Y, Zhao H, Lin Y, Man Y, Wang S, Yang J \& Li J 2010 The effects of palmitate on hepatic insulin resistance are mediated by NADPH oxidase 3-derived reactive oxygen species through JNK and p38MAPK pathways. Journal of Biological Chemistry 285 29965-29973. (https://doi.org/10.1074/jbc.M110.128694)

Hsing LC, Kirk EA, Mcmillen TS, Hsiao SH, Caldwell M, Houston B, Rudensky AY \& Leboeuf RC 2010 Roles for cathepsins S, L, and B in insulitis and diabetes in the NOD mouse. Journal of Autoimmunity $\mathbf{3 4}$ 96-104. (https://doi.org/10.1016/j.jaut.2009.07.003)

Jordans S, Jenko-Kokalj S, Kühl NM, Tedelind S, Sendt W, Brömme D, Turk D \& Brix K 2009. Monitoring compartment-specific substrate cleavage by cathepsins $\mathrm{B}, \mathrm{K}, \mathrm{L}$, and $\mathrm{S}$ at physiological $\mathrm{pH}$ and redox conditions. BMC Biochemistry 1023

Jung TW, Yoo HJ \& Choi KM 2016 Implication of hepatokines in metabolic disorders and cardiovascular diseases. BBA Clinical 5 108-113. (https://doi.org/10.1016/j.bbacli.2016.03.002)

Kady NM, Liu X, Lydic TA, Syed MH, Navitskaya S, Wang Q, Hammer SS, O'Reilly S, Huang C, Seregin SS, et al. 2018 ELOVL4-mediated production of very long-chain ceramides stabilizes tight junctions and prevents diabetes-induced retinal vascular permeability. Diabetes 67 769-781. (https://doi.org/10.2337/db17-1034)

Kuester D, Lippert H, Roessner A \& Krueger S 2008 The cathepsin family and their role in colorectal cancer. Pathology, Research and Practice 204 491-500. (https://doi.org/10.1016/j.prp.2008.04.010)

Lafarge JC, Pini M, Pelloux V, Orasanu G, Hartmann G, Venteclef N, Sulpice T, Shi GP, Clément K \& Guerre-Millo M 2014 Cathepsin $\mathrm{S}$ inhibition lowers blood glucose levels in mice. Diabetologia 57 1674-1683. (https://doi.org/10.1007/s00125-014-3280-2)

Latorre R, Sternini C, De Giorgio R \& Greenwood-Van Meerveld B 2016 Enteroendocrine cells: a review of their role in brain-gut communication. Neurogastroenterology and Motility 28 620-630. (https://doi.org/10.1111/nmo.12754) https://joe.bioscientifica.com

https://doi.org/10.1530/JOE-20-0408
(C) 2021 Society for Endocrinology Published by Bioscientifica Ltd. Printed in Great Britain 
Lee TK, Cheung VC, Lu P, Lau EY, Ma S, Tang KH, Tong M, Lo J \& Ng IO 2014 Blockade of CD47-mediated cathepsin S/protease-activated receptor 2 signaling provides a therapeutic target for hepatocellular carcinoma. Hepatology 60 179-191. (https://doi.org/10.1002/ hep.27070)

Liu J, Ma L, Yang J, Ren A, Sun Z, Yan G, Sun J, Fu H, Xu W, Hu C, et al. 2006 Increased serum cathepsin $S$ in patients with atherosclerosis and diabetes. Atherosclerosis 186 411-419. (https://doi.org/10.1016/j. atherosclerosis.2005.08.001)

Maimaitiyiming H, Norman H, Zhou Q \& Wang S 2015 CD47 deficiency protects mice from diet-induced obesity and improves whole body glucose tolerance and insulin sensitivity. Scientific Reports 58846. (https://doi.org/10.1038/srep08846)

Meex RCR \& Watt MJ 2017 Hepatokines: linking nonalcoholic fatty liver disease and insulin resistance. Nature Reviews: Endocrinology 13 509-520. (https://doi.org/10.1038/nrendo.2017.56)

Meex RC, Hoy AJ, Morris A, Brown RD, Lo JC, Burke M, Goode RJ, Kingwell BA, Kraakman MJ, Febbraio MA, et al. 2015 Fetuin $\mathrm{B}$ is a secreted hepatocyte factor linking steatosis to impaired glucose metabolism. Cell Metabolism 22 1078-1089. (https://doi. org/10.1016/j.cmet.2015.09.023)

Mehrfeld C, Zenner S, Kornek M \& Lukacs-Kornek V 2018 The contribution of non-professional antigen-presenting cells to immunity and tolerance in the liver. Frontiers in Immunology 9635. (https://doi.org/10.3389/fimmu.2018.00635)

Mohktar RA, Montgomery MK, Murphy RM \& Watt MJ 2016 Perilipin 5 is dispensable for normal substrate metabolism and in the adaptation of skeletal muscle to exercise training. American Journal of Physiology: Endocrinology and Metabolism 311 E128-E137. (https://doi org/10.1152/ajpendo.00084.2016)

Montgomery MK, Osborne B, Brown SH, Small L, Mitchell TW, Cooney GJ \& Turner N 2013 Contrasting metabolic effects of medium-versus long-chain fatty acids in skeletal muscle. Journal of Lipid Research 54 3322-3333. (https://doi.org/10.1194/jlr.M040451)

Montgomery MK, Fiveash CE, Braude JP, Osborne B, Brown SHJ, Mitchell TW \& Turner N 2015 Disparate metabolic response to fructose feeding between different mouse strains. Scientific Reports $\mathbf{5}$ 18474. (https://doi.org/10.1038/srep18474)

Naour N, Rouault C, Fellahi S, Lavoie ME, Poitou C, Keophiphath M, Eberlé D, Shoelson S, Rizkalla S, Bastard JP, et al. 2010 Cathepsins in human obesity: changes in energy balance predominantly affect cathepsin S in adipose tissue and in circulation. Journal of Clinical Endocrinology and Metabolism 95 1861-1868. (https://doi.org/10.1210/ jc.2009-1894)

Nauck MA \& Meier JJ 2018 Incretin hormones: their role in health and disease. Diabetes, Obesity and Metabolism 20 (Supplement 1) 5-21. (https://doi.org/10.1111/dom.13129)

Nørgaard SA, Briand F, Sand FW, Galsgaard ED, Søndergaard H, Sørensen DB \& Sulpice T 2019 Nephropathy in diabetic db/db mice is accelerated by high protein diet and improved by the SGLT2 inhibitor dapagliflozin. European Journal of Pharmacology $\mathbf{8 6 0}$ 172537. (https:// doi.org/10.1016/j.ejphar.2019.172537)

Oh KJ, Lee DS, Kim WK, Han BS, Lee SC \& Bae KH 2016 Metabolic adaptation in obesity and type II diabetes: myokines, adipokines and hepatokines. International Journal of Molecular Sciences 18 8. (https:// doi.org/10.3390/ijms18010008)

Pal D, Dasgupta S, Kundu R, Maitra S, Das G, Mukhopadhyay S, Ray S, Majumdar SS \& Bhattacharya S 2012 Fetuin-A acts as an endogenous ligand of TLR4 to promote lipid-induced insulin resistance. Nature Medicine 18 1279-1285. (https://doi.org/10.1038/ nm.2851)

Rana R, Shearer AM, Fletcher EK, Nguyen N, Guha S, Cox DH, Abdelmalek M, Wang Y, Baleja JD, Covic L, et al. 2019 PAR2 controls cholesterol homeostasis and lipid metabolism in nonalcoholic fatty liver disease. Molecular Metabolism 29 99-113. (https://doi. org/10.1016/j.molmet.2019.08.019)
Rawlings ND \& Salvesen G 2012 Handbook of Proteolytic Enzymes (Electronic Resource). Academic Press.

Rogers NM, Sharifi-Sanjani M, Csányi G, Pagano PJ \& Isenberg JS 2014 Thrombospondin-1 and CD47 regulation of cardiac, pulmonary and vascular responses in health and disease. Matrix Biology 37 92-101. (https://doi.org/10.1016/j.matbio.2014.01.002)

Schirra J, Sturm K, Leicht P, Arnold R, Göke B \& Katschinski M 1998 Exendin(9-39)amide is an antagonist of glucagon-like peptide-1(7-36) amide in humans. Journal of Clinical Investigation 101 1421-1430. (https://doi.org/10.1172/JCI1349)

Sébert M, Sola-Tapias N, Mas E, Barreau F \& Ferrand A 2019 Proteaseactivated receptors in the intestine: focus on inflammation and cancer. Frontiers in Endocrinology 10 717. (https://doi.org/10.3389/ fendo.2019.00717)

Shearer AM, Rana R, Austin K, Baleja JD, Nguyen N, Bohm A, Covic L \& Kuliopulos A 2016 Targeting liver fibrosis with a cell-penetrating protease-activated receptor-2 (PAR2) pepducin. Journal of Biological Chemistry 291 23188-23198. (https://doi.org/10.1074/jbc. M116.732743)

Steinberg GR \& Dyck DJ 2000 Development of leptin resistance in rat soleus muscle in response to high-fat diets. American Journal of Physiology: Endocrinology and Metabolism 279 E1374-E1382. (https:// doi.org/10.1152/ajpendo.2000.279.6.E1374)

Takiyama Y, Sera T, Nakamura M, Ishizeki K, Saijo Y, Yanagimachi T, Maeda M, Bessho R, Takiyama T, Kitsunai H, et al. ,et al. et al.2018 Impacts of diabetes and an SGLT2 inhibitor on the glomerular number and volume in $\mathrm{db} / \mathrm{db}$ mice, as estimated by synchrotron radiation micro-CT at SPring-8. EBiomedicine 36 329-346. (https://doi. org/10.1016/j.ebiom.2018.09.048)

Taleb S, Lacasa D, Bastard JP, Poitou C, Cancello R, Pelloux V, Viguerie N, Benis A, Zucker JD, Bouillot JL, et al. 2005 Cathepsin S, a novel biomarker of adiposity: relevance to atherogenesis. FASEB Journal 19 1540-1542. (https://doi.org/10.1096/fj.05-3673fje)

Taleb S, Cancello R, Poitou C, Rouault C, Sellam P, Levy P, Bouillot JL, Coussieu C, Basdevant A, Guerre-Millo M, et al. 2006 Weight loss reduces adipose tissue cathepsin $\mathrm{S}$ and its circulating levels in morbidly obese women. Journal of Clinical Endocrinology and Metabolism 91 1042-1047. (https://doi.org/10.1210/jc.2005-1601)

Verrijn Stuart AA, Schipper HS, Tasdelen I, Egan DA, Prakken BJ, Kalkhoven E \& De Jager W 2012 Altered plasma adipokine levels and in vitro adipocyte differentiation in pediatric type 1 diabetes. Journal of Clinical Endocrinology and Metabolism 97 463-472. (https://doi. org/10.1210/jc.2011-1858)

Vidak E, Javoršek U, Vizovišek M \& Turk B 2019 Cysteine cathepsins and their extracellular roles: shaping the microenvironment. Cells 8264 . (https://doi.org/10.3390/cells8030264)

Wang J, Chakrabarty S, Bui Q, Ruf W \& Samad F 2015 Hematopoietic tissue factor-protease-activated receptor 2 signaling promotes hepatic inflammation and contributes to pathways of gluconeogenesis and steatosis in obese mice. American Journal of Pathology 185 524-535. (https://doi.org/10.1016/j.ajpath.2014.10.008)

Watt MJ, Miotto PM, De Nardo W \& Montgomery MK 2019 The liver as an endocrine organ - linking NAFLD and insulin resistance. Endocrine Reviews 40 1367-1393. (https://doi.org/10.1210/er.2019-00034)

Whitmore L \& Wallace BA 2004 DICHROWEB, an online server for protein secondary structure analyses from circular dichroism spectroscopic data. Nucleic Acids Research 32 W668-W673. (https:// doi.org/10.1093/nar/gkh371)

Wilkinson RD, Williams R, Scott CJ \& Burden RE 2015 Cathepsin S: therapeutic, diagnostic, and prognostic potential. Biological Chemistry 396 867-882. (https://doi.org/10.1515/hsz-2015-0114)

Windeløv JA, Wewer Albrechtsen NJ, Kuhre RE, Jepsen SL, Hornburg D, Pedersen J, Jensen EP, Galsgaard KD, Winther-Sørensen M, Ørgaard A, et al. 2017 Why is it so difficult to measure glucagon-like peptide-1 in a mouse? Diabetologia 60 2066-2075. (https://doi.org/10.1007/ s00125-017-4347-7) https://joe.bioscientifica.com

https://doi.org/10.1530/JOE-20-0408 (c) 2021 Society for Endocrinology Published by Bioscientifica Ltd. Printed in Great Britain 
Xiong X, Kuang H, Ansari S, Liu T, Gong J, Wang S, Zhao XY, Ji Y, Li C, Guo L, et al. 2019 Landscape of intercellular crosstalk in healthy and NASH liver revealed by single-cell secretome gene analysis. Molecular Cell 75 644.e5-660.e5. (https://doi.org/10.1016/j.molcel.2019.07.028)

Xu L, Feng B, Wang H \& Li X 2013 Multiple statistical methods for assessing differential gene expression in microarray data of diabetic model rats to predict the molecular mechanism of atorvastatin on anti-atherogenesis. Experimental and Clinical Endocrinology and Diabetes 121 272-279. (https://doi.org/10.1055/s-0033-1334955)

Yang H, Yang T, Heng C, Zhou Y, Jiang Z, Qian X, Du L, Mao S, Yin X \& Lu Q 2019 Quercetin improves nonalcoholic fatty liver by ameliorating inflammation, oxidative stress, and lipid metabolism in db/db mice. Phytotherapy Research 33 3140-3152. (https://doi. org/10.1002/ptr.6486)

Received in final form 19 November 2020

Accepted 2 December 2020

Accepted Manuscript published online 8 December 2020 (c) 2021 Society for Endocrinology Published by Bioscientifica Ltd.
Printed in Great Britain 